\title{
Effect of temperature on the fiber/matrix interfacial strength of carbon fiber reinforced polyamide model composites
}

\author{
Kazuto TANAKA*, Nanako HOSOO*, Tsutao KATAYAMA*, \\ Yuki NOGUCHI** and Kazuhiro IZUI** \\ * Department of Biomedical Engineering, Doshisha University \\ 1-3, Tatara-miyakodani, Kyotanabe, Kyoto 610-0394, Japan \\ E-mail: ktanaka@mail.doshisha.ac.jp \\ ** Department of Mechanical Engineering and Science, Kyoto University \\ C3, Kyotodaigaku-Katsura, Nishikyo-ku, Kyoto 615-8540, Japan
}

Received 3 March 2016

\begin{abstract}
Carbon Fiber Reinforced Thermoplastics (CFRTP) have attracted attention in the automotive industry for their productivity and high specific strength and modulus. To guarantee the durability of CFRTP, it is important to understand the mechanical properties of CFRTP under practical service temperature. Since the mechanical properties of CFRTP are affected not only by reinforcement fibers and matrix resins but also by the fiber matrix interface, to reveal the fiber/matrix interface properties is one of the important issues to be solved. Among thermoplastic resins, polyamide (PA) is expected to be used for the matrix of CFRTP, owing to good interfacial adhesion to the carbon fiber, and good moldability. Although tensile tests of CFRTP under the high temperature environment were performed, the effects of temperature on the fiber/matrix interfacial shear strength have not been fully clarified. In this study, in order to evaluate the fiber/matrix interfacial properties at $25^{\circ} \mathrm{C}, 40{ }^{\circ} \mathrm{C}$ and $80{ }^{\circ} \mathrm{C}$, single fiber pull-out tests, measurement of the thermal expansion coefficient of the resin, and analysis of the thermal expansion of the resin were performed. As temperature rose, resin expanded and interfacial shear strength of the CF/PA model composites decreased. This result suggests that the decrease of the interfacial shear strength by temperature rise is caused by the expansion of the resin.
\end{abstract}

Key words : Fiber/matrix interfacial shear strength, Polyamide, Carbon fiber, Pull-out test, High temperature

\section{Introduction}

In order to obtain good gasoline mileage in mass-produced automobiles, to reduce the weight of a car body by using Carbon Fiber Reinforced Thermoplastics (CFRTP) has attracted attention as thermoplastics are excellent in productivity and recyclability. (Asmatule et al., 2013) (Matsutsuka et al., 2005) Among thermoplastic resins, polyamide (PA) is expected to be used for the matrix of CFRTP, owing to good interfacial adhesion to the carbon fiber, and good moldability. (Beckwith, 2008) To apply CFRTP to automobiles, it is important to understand the mechanical properties of CFRTP under practical service temperature. For example, the roof components, which have the highest temperature among vehicle structural components, rise up to $83.5{ }^{\circ} \mathrm{C}$ under the scorching sun. (JIS D 0204, 1967) Since the mechanical properties of CFRTP are affected not only by reinforcement fibers and matrix resins but also by the fiber matrix interface, it is necessary to consider the effects of temperature on the fiber/matrix interfacial properties of CFRTP. (Sethi and Ray, 2015) Vieille et al reported that the tensile strength of CF/PPS under a high temperature environment was smaller than that of a room temperature one, and by SEM observation of fracture surfaces, the degradation of fiber/matrix interfacial properties was considered to be the reason for this. (Vieille and Taleb, 2011) However, the effects of temperature on the fiber/matrix interfacial properties have not been evaluated. Although a large quantity of data on the fiber/matrix interfacial properties of composites can be obtained in carbon fiber reinforced 
thermoset composites (CFRP), data on the fiber/matrix interfacial properties of CFRTP is not sufficiently available compared with CFRP. (Kim and Mai, 1998) (Koyanagi et al., 2010) (Koyanagi et al., 2011) (Sethi and Ray, 2015) (Tanaka et al., 2002) (Tanaka et al., 2003) In this study, in order to evaluate the fiber/matrix interfacial properties at $25{ }^{\circ} \mathrm{C}, 40{ }^{\circ} \mathrm{C}$ and $80{ }^{\circ} \mathrm{C}$, single fiber pull-out tests, measurement of the thermal expansion coefficient of the resin, and analysis of the thermal expansion of the resin were performed, and the degradation mechanism of the fiber/matrix interfacial properties at high temperature was discussed.

\section{Materials and Experimental procedure 2.1 Materials}

PAN-based carbon fibers were used for the single fiber pull-out tests. Polyamide 6 (PA6: 1013B, Ube Industries, Ltd., Japan) and Polyamide 12 (PA12: 3014U, Ube Industries, Ltd., Japan) were used for the matrix.

\subsection{Single fiber pull-out test}

Figure 1 shows the shape and dimension of a pull-out specimen. After a single carbon fiber was glued to a tab, it was attached to a micromanipulator. PA resin was placed on the aluminum plate heated to $250{ }^{\circ} \mathrm{C}$ for PA6 and $220{ }^{\circ} \mathrm{C}$ for PA12.

After the single fiber was embedded into the melted resin by operating the micromanipulator, it was air-cooled. These specimens are referred to as CF/PA model composites, and these CF/PA model composites were used for single fiber pull-out tests. After chucking the tab of a pull-out specimen, the supporting part of the tab was cut and a pull-out test was performed using a testing machine for micro material (MMT-11 N, Shimadzu Co., Japan, Load capacity: $10 \mathrm{~N}$ ) with a constant displacement rate of $1.67 \times 10^{-6} \mathrm{~m} / \mathrm{s}$. The temperature condition at room temperature was $25^{\circ} \mathrm{C}$ and the single fiber pull-out tests under the high temperatures of $40{ }^{\circ} \mathrm{C}$ and $80{ }^{\circ} \mathrm{C}$ were conducted on the hot plates as shown in Fig. 2. Figure 3 shows a schematic drawing of an embedded fiber and Figure 4 shows a pulled-out fiber observed by scanning electron microscope (SEM, JSM-6390LT, JEOL Ltd., Japan). The precise embedded fiber length and fiber diameter were measured by using SEM after the pull-out tests. The fiber/matrix interfacial shear strength, $\tau$, was calculated by the following Eq. (1):

$$
\tau=\frac{F_{\max }}{\pi d l}
$$

where $F_{\text {max }}$ is the maximum load in the pull-out test, $d$ is the fiber diameter and $l$ is the embedded fiber length.

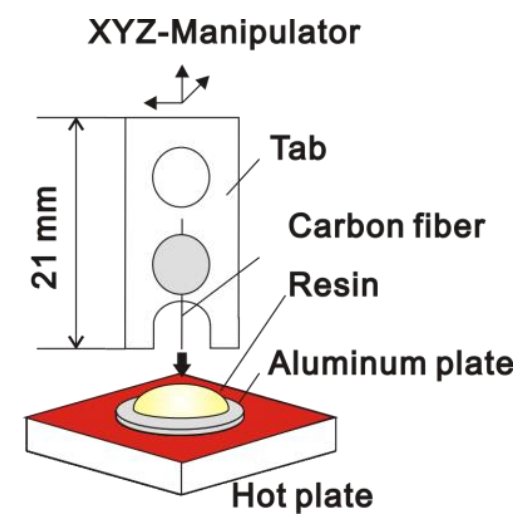

Fig. 1 Shape and dimension of a pull-out specimen. 


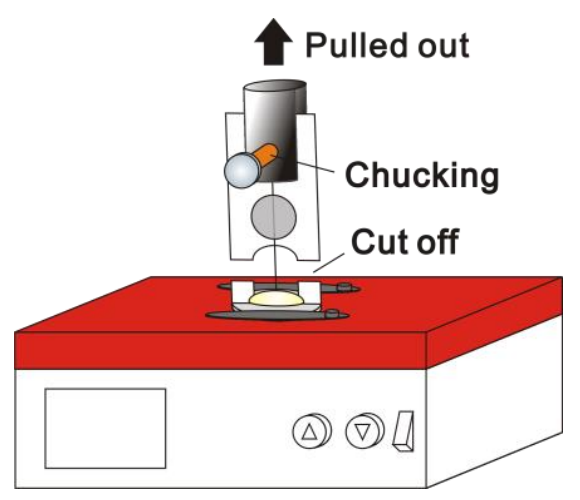

Fig. 2 Schematic view of pull-out test at high temperature.

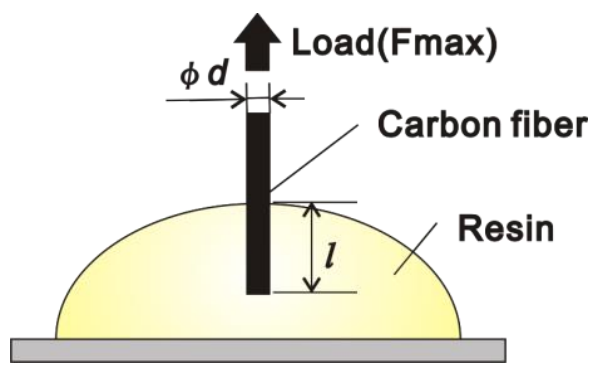

Fig. 3 Schematic drawing of an embedded fiber.

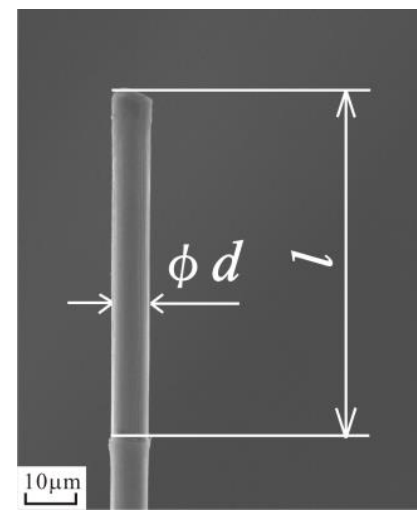

Fig. 4 SEM observation of a pulled-out specimen.

\subsection{Measurement of thermal expansion coefficient of resins}

The thermal expansion coefficients of PA6 and PA12 were measured by a thermomechanical analyzer (TMA-60, Shimadzu Co., Japan). The testing load was $2 \mathrm{~g}$, the rate of temperature rise was $3{ }^{\circ} \mathrm{C} / \mathrm{min}$, and the temperature conditions for the resins were from $30{ }^{\circ} \mathrm{C}$ to $140{ }^{\circ} \mathrm{C}$. The thermal expansion coefficient was calculated using the following Eq. (2):

$$
\Delta L=L a \Delta T
$$

where $\Delta L$ is the displacement, $L$ is the original length, $\alpha$ is the thermal expansion coefficient and $\Delta T$ is the difference of temperature. 


\subsection{Analysis of the thermal expansion}

FEM analysis to estimate the thermal expansion of the resins as temperature rose was conducted using the commercial FEM software COMSOL Multiphysics 4.4. The analysis was performed using coupled analysis including a structural mechanics module and heat transfer module. Figure 5 shows the analyzed model of the resin. The hemispherical resin made of polyamide, whose size is $3 \mathrm{~mm}$ in diameter and $1.5 \mathrm{~mm}$ in depth, has a cylindrical hole. The size of the hole is $7 \mu \mathrm{m}$ in diameter and $50 \mu \mathrm{m}$ in length, in which a carbon fiber is embedded. The total number of tetrahedral elements was 119,178 . The initial temperature of the resin was set to $25^{\circ} \mathrm{C}$. The boundary conditions were selected as shown in Fig. 6. The bottom surface was set to $40{ }^{\circ} \mathrm{C}$ and $80{ }^{\circ} \mathrm{C}$. To consider the heat transfer to the air, the air contact surface was set as the heat transfer condition. The constraint conditions were selected as shown in Fig. 7. For the constraint conditions of the bottom surface, only the displacement of the $\mathrm{x}$ direction was set to zero. The center of the bottom surface was fixed. The material properties used in this analysis are shown in Table 1. The thermal conductivity $(\lambda)$, Young's modulus (E) and Poisson's ratio $(v)$ of the dried resins of PA6 and PA12 at room temperature were provided by Ube Industries, Ltd.

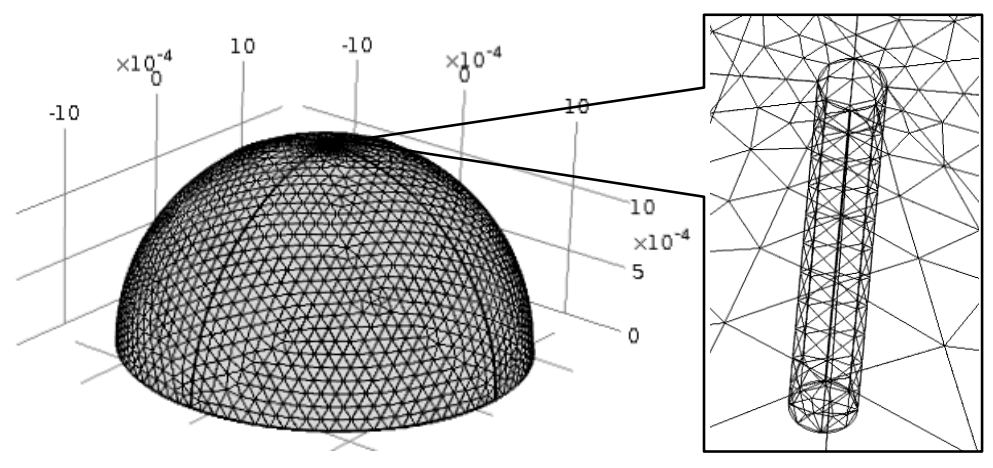

Fig. 5 Analyzed model of the resin.

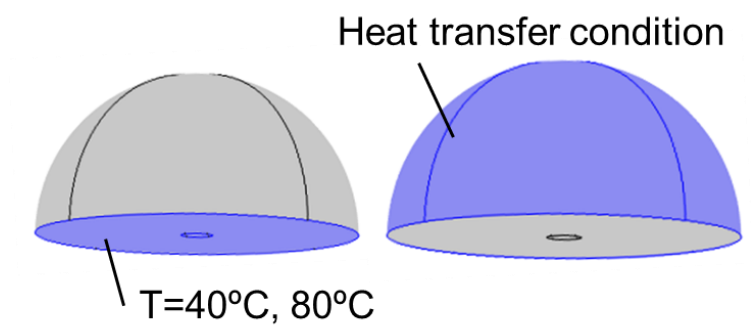

Fig. 6 Boundary conditions of analyzed model.
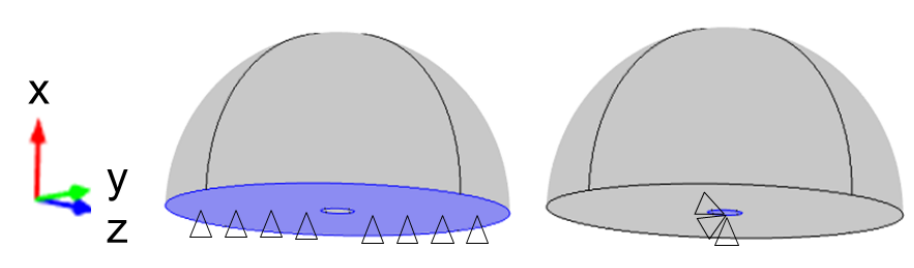

Fig. 7 Constraint conditions of analyzed model. 
Table 1 Material properties of polyamide resins.

\begin{tabular}{c|c|c}
\hline \hline & PA6 & PA12 \\
\hline Thermal conductivity $(\lambda)[\mathrm{W} / \mathrm{m} \cdot \mathrm{K}]$ & 0.24 & 0.22 \\
Young's modulus $(\mathrm{E})[\mathrm{GPa}]$ & 2.47 & 1.27 \\
Poisson's ratio $(v)$ & 0.39 & 0.42 \\
\hline
\end{tabular}

\section{Results and discussion}

\subsection{Thermal expansion coefficient of resins}

Figure 8 shows the relationship between time and temperature, and displacement of PA6 and PA12. Figure 9 shows the calculated coefficients of the thermal expansion of PA6 and PA12. These results show that the thermal expansion coefficients of both resins increased as temperature rose, and that of PA12 was higher than that of PA6 regardless of the measured temperature.

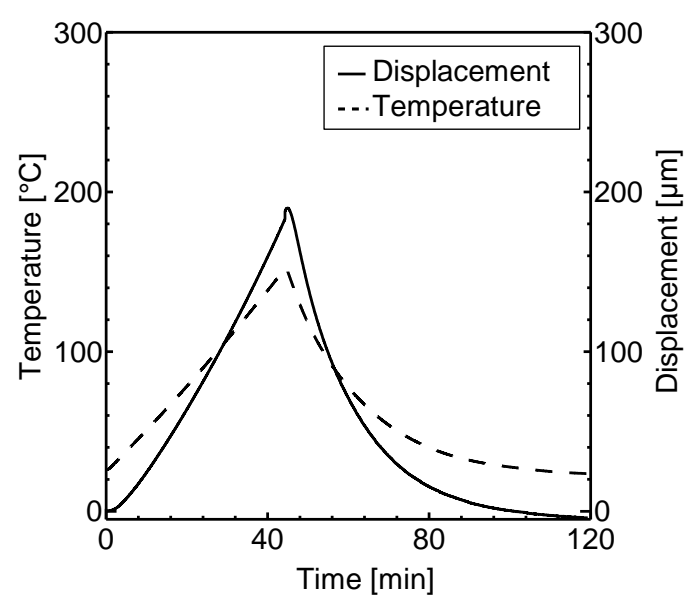

(a) PA6

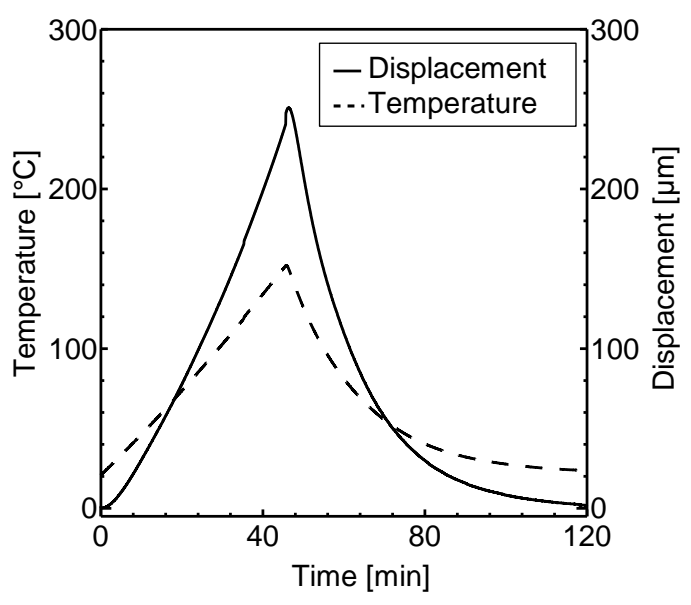

(b) PA12

Fig. 8 Relationship between time and temperature, and displacement of (a) PA6 and (b) PA12.

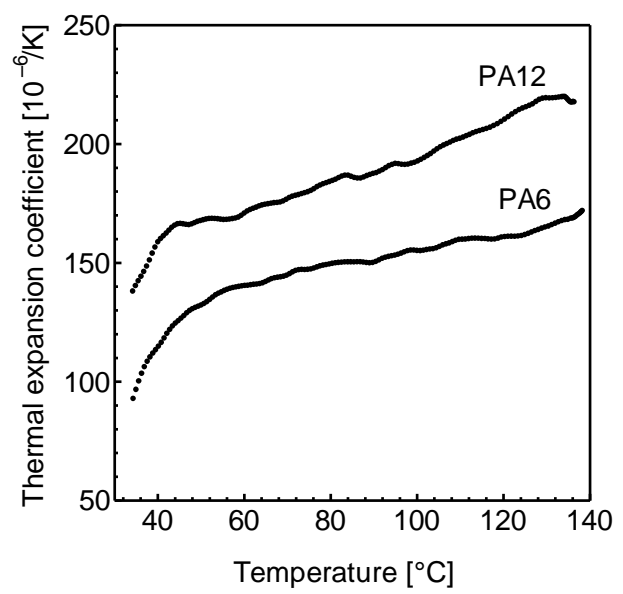

Fig. 9 Thermal expansion coefficients of PA6 and PA12. 


\subsection{Single fiber pull-out test}

Figure 10 shows the fiber/matrix interfacial shear strengths of CF/PA6 and CF/PA12 obtained by the single fiber pull-out tests. The fiber/matrix interfacial shear strengths of CF/PA6 model composites at $25{ }^{\circ} \mathrm{C}, 40{ }^{\circ} \mathrm{C}$ and $80{ }^{\circ} \mathrm{C}$ were 43.2 $\mathrm{MPa}, 34.9 \mathrm{MPa}$ and $24.4 \mathrm{MPa}$, respectively. On the other hand, those of CF/PA12 model composites at $25{ }^{\circ} \mathrm{C}$, $40{ }^{\circ} \mathrm{C}$ and $80{ }^{\circ} \mathrm{C}$ were $30.3 \mathrm{MPa}, 23.2 \mathrm{MPa}$ and $20.4 \mathrm{MPa}$, respectively. The results show that the fiber/matrix interfacial shear strengths of CF/PA6 model composites were decreased by $20 \%$ at $40{ }^{\circ} \mathrm{C}$ and $44 \%$ at $80{ }^{\circ} \mathrm{C}$. And those of CF/PA12 model composites were decreased by $24 \%$ at $40{ }^{\circ} \mathrm{C}$ and $33 \%$ at $80{ }^{\circ} \mathrm{C}$. The interfacial shear strengths of both specimens decreased as temperature rose.

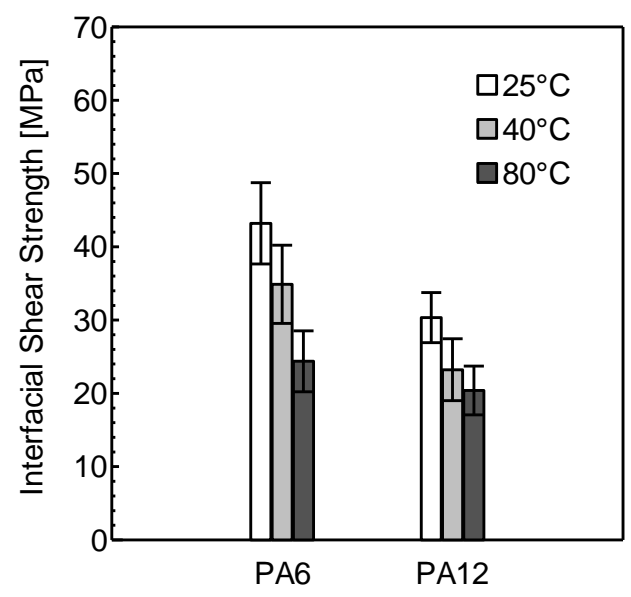

Fig. 10 Interfacial shear strength.

\subsection{Analysis of the thermal expansion of resin}

Figure 11 shows displacement distributions of the analyzed resin model. Figure 12 shows the enlarged views of the holes of PA6 and PA12 at $40{ }^{\circ} \mathrm{C}$ and $80{ }^{\circ} \mathrm{C}$. The solid lines are outlines at $25^{\circ} \mathrm{C}$ and the dotted lines are those at heated temperature. Figure 13 shows the hole diameter of both resins at each temperature. The hole diameter of PA6 was increased by $0.26 \%$ at $40{ }^{\circ} \mathrm{C}$ and $0.79 \%$ at $80{ }^{\circ} \mathrm{C}$ compared with that at $25{ }^{\circ} \mathrm{C}$. And the hole diameter of PA12 was increased by $0.31 \%$ at $40{ }^{\circ} \mathrm{C}$ and $0.92 \%$ at $80{ }^{\circ} \mathrm{C}$ compared with that at $25^{\circ} \mathrm{C}$. These results show that the hole diameter of both resins increased as temperature rose. Figure 14 shows the relationship between interfacial shear strength and hole diameter. The interfacial shear strengths of both specimens decreased as hole diameter rose. Wang et al reported that the residual thermal stress in the radial direction, which is formed during cooling of the micro-droplet from melting to ambient temperature, affects the interfacial shear strength of a CF/PPS composite evaluated by micro bond test (Wang et al., 2015). These results show that the interfacial shear strength decreases by temperature rise due to the reduction of the residual thermal stress in the radial direction caused by thermal expansion of the hole of the resin in the radial direction.

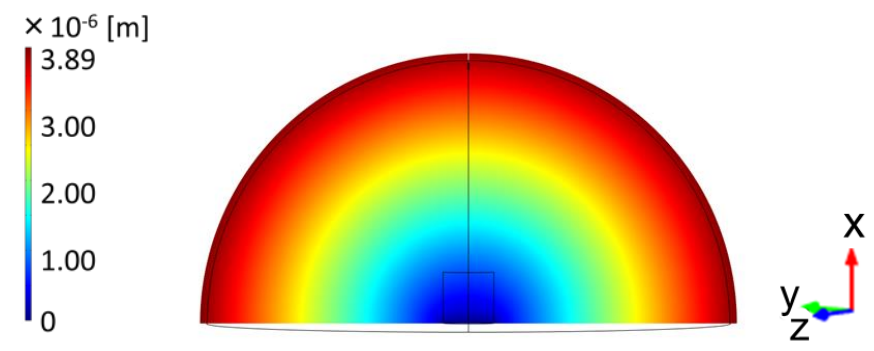

Fig. 11 Displacement distributions of the analyzed model. 


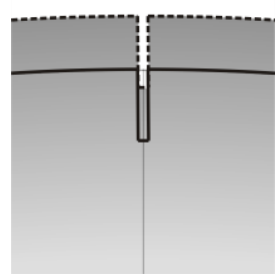

(a) PA6 at $40^{\circ} \mathrm{C}$

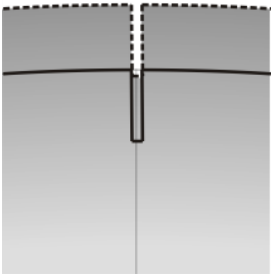

(b) PA12 at $40{ }^{\circ} \mathrm{C}$

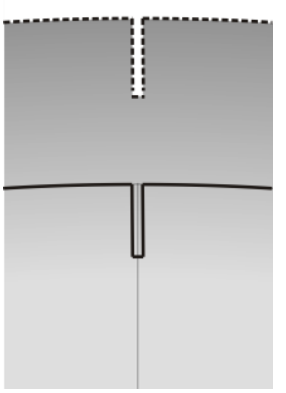

(c) PA6 at $80^{\circ} \mathrm{C}$

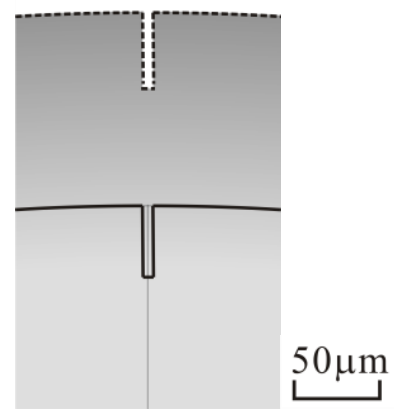

(d) PA12 at $80^{\circ} \mathrm{C}$

Fig. 12 Enlarged views of the holes.

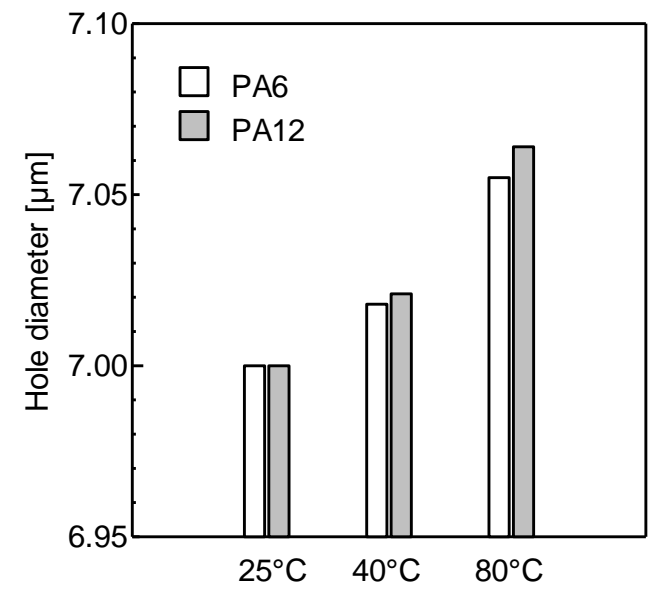

Fig. 13 Hole diameter of both resins at each temperature.

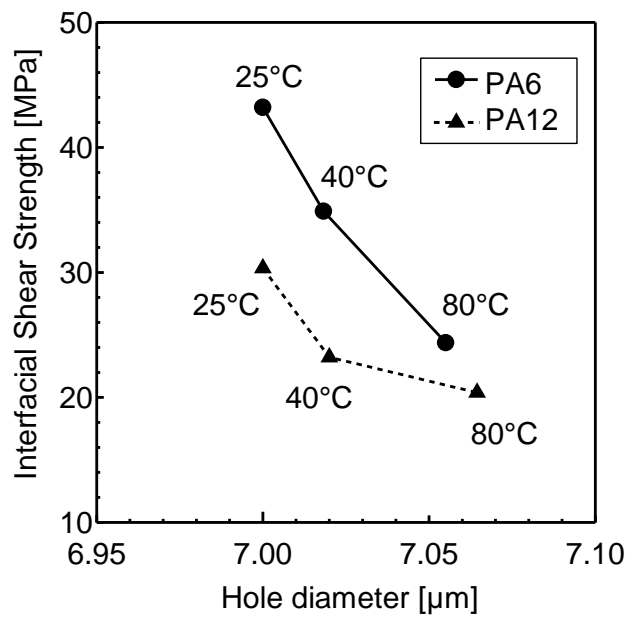

Fig. 14 Relationship between interfacial shear strength and hole diameter. 


\section{Conclusion}

To investigate the effects of temperature on the fiber/matrix interfacial properties of CF/PA6 and CF/PA12 model composites, single fiber pull-out tests at $25^{\circ} \mathrm{C}, 40^{\circ} \mathrm{C}$ and $80{ }^{\circ} \mathrm{C}$, measurement of the thermal expansion coefficient of the resin, and analysis of the thermal expansion of the resin were conducted. The investigation yielded the following conclusions:

1. Interfacial shear strengths of both CF/PA6 and CF/PA12 model composites decreased as temperature rose.

2. The thermal expansion coefficients of both resins increased as temperature rose and that of PA12 was higher than that of PA6 regardless of the measured temperature.

3. From FEM analysis of the hole diameter of resins at high temperature, hole diameters of both resins increased as temperature rose. These results suggest that the interfacial shear strength decreases by temperature rise due to the reduction of the residual thermal stress in the radial direction caused by thermal expansion of the hole of the resin in the radial direction.

\section{References}

Asmatulu, E., Twomey, J. and Overcash, M., Recycling of fiber-reinforced composites and direct structural composite recycling concept, Journal of Composite Materials, Vol.48, No.5 (2013), pp.593-608.

Beckwith, S. W., Thermoplastic composite resin matrices, SAMPE Journal, Vol.44, No.1 (2008), pp.70-71.

Kim, J. K. and Mai, Y. W., Engineered interfaces in fiber reinforced composites (1998), ELSEVIER.

Koyanagi, J., Kawai, J., Ogihara, S. and Watanabe, K., Carbon fiber/matrix interfacial shear strength evaluated by single fiber pull-out test considering effects of resin meniscus, Experimental Mechanics, Vol.10 (2010), pp.407-412.

Koyanagi, J. and Ogihara, S., Temperature dependence of glass fiber/epoxy interface normal strength examined by a cruciform specimen method, Composites: Part B, Vol.42 (2011), pp.1492-1496.

Matsutsuka, N., Takahashi, J., Zushi, H., Osawa, I. and Uzawa, K., Evaluation of recycled CFRTP for mass production applications, The Ninth Japan International SAMPE symposium (2005), pp.50-55.

Method of high and low temperature test for automobile parts, JIS D 0204 (1967), pp.6-7.

Sethi, S. and Ray, B. C., Environmental effects on fibre reinforced polymeric composites: Evolving reasons and remarks on interfacial strength and stability, Advances in Colloid and Interface Science 217 (2015), pp.43-67.

Tanaka, K., Minoshima, K., Grela, W. and Komai, K., Characterization of the aramid/epoxy interfacial properties by means of pull-out test and influence of water absorption, Composites Science and Technology, Vol.62 (2002), pp.2169-2177.

Tanaka, K., Minosima, K., Grela, W., Araki, Y. and Komai, K., Evaluation of the fiber/matrix interfacial properties under static and fatigue loading using model composites, Proceedings of the annual meeting of JSME/MMD, Vol.2003 (2003), pp.189-190.

Vieille, B. and Taleb, L., About the influence of temperature and matrix ductility on the behavior of carbon woven-ply PPS or epoxy laminates: Notched and unnotched laminates, Composites Science and Technology, Vol.71 (2011), pp.998-1007.

Wang, X., Xu, D., Liu, H., Zhou, H., Mai, Y., Yang, J. and Li, E., Effects of thermal residual stress on interfacial properties of polyphenylene sulphide/carbon fiber (PPS/CF) composite by microbond test, Journal of Materials Science, Vol.51 (2015), pp.334-343. 